\title{
NENHUM A MENOS: \\ É POSSIVEL NÃO DEIXAR NINGUÉM PARA TRÁS?
}

Ana Lúca Tarouquella Schilke

Universidade Federal Fluminense

\section{Resumo}

O presente texto tem por objetivo pensar as questões que subjazem ao tema da avaliação, a partir da experiência pedagógica desenvolvida com um aluno da Rede pública de Educação. O trabalho justifica-se, pois diversos alunos escapam cotidianamente aos olhos dos docentes, e estes, em sua maioria, não problematizam a sua responsabilidade e real possibilidade de ação frente a este problema. Subjugados a políticas educacionais centradas em exames externos de larga escala, os professores acabam por alimentar a lógica neoliberal, contribuindo para o apagamento das diferenças sociais e culturais. Mesmo com tal cenário identificado, as práticas normatizantes e as emancipadoras, que convivem e disputam o território pedagógico, abrem portas às experiências vividas no cotidiano escolar que têm potencial de transformar relações, indicando caminhos, brechas, desvios que corroboram para a escola, verdadeiramente, para todos.

Palavras-chave:

Avaliação; Experiência pedagógica; Política educacional. 


\title{
NO ONE BEHIND \\ IS IT POSSIBLE NOT TO LEAVE ANYONE BEHIND?
}

\begin{abstract}
This text aims to think the issues that underlie the subject of assessment, from the educational experience developed with a student of the public education system. The work is justified because every day many students escape the eyes of teachers who mostly do not question the responsibility and real possibility of action against this problem. Subjugated to educational policies focusing on large scale external exams, teachers end up fueling the neoliberal logic that contributes to erasing the social and cultural differences. Even with such identified scenario, the standard and emancipatory practices, that coexist and dispute the educational territory, open doors to experiences in everyday school-life that have the potential to transform relationships, indicating paths, gaps and deviations that support for a truly everyone school.
\end{abstract}

Keywords: Assessment; Teaching experience; Educational policy . 
O presente texto tem por objetivo pensar as questões que subjazem ao tema da avaliação em relação ao sucesso/fracasso escolar. Parto da possibilidade da aprendizagem ser compreendida como direito de todos, garantida não só pelo acesso e permanência na escola, mas, fundamentalmente, pelo compromisso com o sucesso escolar dos seus alunos. Terei como desafio estabelecer relações entre os aspectos micro e macro das políticas educacionais, tomando como ponto de referência a experiência pedagógica desenvolvida com um aluno da Rede Municipal de Educação de Niterói.

Trago, como título do artigo, o nome de um filme em que se materializam os desafios enfrentados por uma "professora" no interior da China. Apesar da distância territorial, é possível identificar algumas aproximações entre o vivido pela protagonista do filme e as docentes no Brasil. Não deixar nenhum aluno escapar da escola, o que foi o grande dilema vivenciado pela personagem, e consequentemente, garantir o sucesso escolar dos alunos, nem sempre tem sido tomado por nós ${ }^{1}$, professoras, como uma opção política de atuação.

Deixamos, cotidianamente, diversos alunos escaparem sem problematizar a nossa responsabilidade e real possibilidade de ação frente a este problema. Parece que tal situação não é desafio a ser enfrentado pelos professores, sendo apenas generalização numérica. Podemos observar o impacto da realidade educacional brasileira a partir dos índices de analfabetismo no Brasil. Segundo dados do IBGE $^{2}$, divulgados em 2012, 13,2 milhões de pessoas entre 15 anos ou mais são consideradas analfabetas ${ }^{3}$. Considerando o debate que se

\footnotetext{
${ }^{1}$ Apesar de ser um texto que fala da minha ação, adoto por vezes o plural por compreender que o meu leitor é também um co-autor.

2 Informações coletadas em 23/11/2013 no site http://g1.globo.com/educacao/noticia/2013/09/indice-deanalfabetismo-para-de-cair-e-fica-em-87-diz-pnad.html

${ }^{3}$ Pessoa que não sabe escrever um bilhete simples no idioma que conhece. Informações coletadas em 23/11/2013 no site http://www.ibge.gov.br/home/estatistica/populacao/condicaodevida/indicadoresminimos/conceitos.shtm
}

Olh@res, Guarulhos, v. 2, n. 1, p. 237-252. Maio, 2014. 
pode travar entre o conceito de alfabetização e o que significa, em termos reais, demonstrar os conhecimentos adquiridos pelos estudantes, os dados revelam defasagem entre o que a escola tem como função e o que realiza de fato.

Se esse número assusta, por ser aproximadamente 26 vezes o número total de habitantes da cidade de Niterói ${ }^{4}$, já sua expressão cotidiana, dentro de uma escola neste mesmo município, parece não causar a mesma indignação. Na escola investigada, a partir dos documentos estudados, encontramos 343 alunos regularmente matriculados no ano 2012. Também foi possível identificar que 89 alunos foram retidos no período 2011-2012 em todos os anos de escolaridade e que 19 estudantes foram considerados evadidos. Isso significa, em dados relativos, que 1/4 dos alunos, regularmente matriculados, escapam a olhos vistos das ações pedagógicas desenvolvidas naquele cenário educacional. Diferentemente da protagonista do filme, não estamos assumindo o sucesso de todos os nossos alunos como opção políticopedagógica. Seria possível não deixar nenhum aluno para trás? Quais as implicações desta opção pedagógica?

\section{Fracasso escolar: marcas de uma concepção de mundo.}

A entrada das classes populares na escola, mais intensamente a partir da década de 90, significou um marco nas políticas de universalização da educação em nosso país. Se for verdade que temos que comemorar o número expressivo de alunos que já estão na escola e que antes estavam à margem da sociedade com o seu direito à educação negligenciado, nossa comemoração se finda exatamente neste ponto, pois a democratização escolar restringe-se ao acesso aos bancos escolares, não ao sucesso pedagógico dos alunos, Para Esteban,

\footnotetext{
${ }^{4} 487.562$ habitantes dados do censo de 2010
} 


\begin{abstract}
A indiscutível democratização do acesso à escola, com a ampliação de vagas em todos os níveis de ensino, não encontra equivalência no acesso ao conhecimento, especialmente para as classes populares. Para estas a escola continua uma promessa por ser efetivamente cumprida" (ESTEBAN, 2012, p.129)
\end{abstract}

Evidenciamos a igualdade de oportunidade, traduzida como acesso à educação, porém não observamos, na mesma medida, igualdade de resultados. Isso ocorre porque na lógica neoliberal diferenças culturais e sociais são transformadas em desigualdades a serem superadas. Nesta lógica, ter acesso à educação é um direito, mas o sucesso escolar seria uma conquista individual relacionada com o investimento pessoal e familiar, associada exclusivamente ao esforço pedagógico do aluno, ao mérito de cada um. Para Freitas, 2012, p 383 "Ela está na base da proposta política liberal: igualdade de oportunidade e não de resultados (...) nada é dito sobre a igualdade de condições no ponto de partida. No caso da escola, diferenças sociais são transmutadas em diferenças de desempenho". Comungando com tais princípios, democratização do acesso e não sucesso escolar em que a aprendizagem é secundarizada e o desempenho ganha a centralidade, as avaliações preconizadas pelos organismos públicos de educação centram suas políticas na avaliação do mérito e a aprendizagem não é um elemento a ser considerado. O dito bom aluno é aquele que apresenta um boa performance e a qualidade da educação é compreendida como a qualidade de desempenho. Assim, as políticas educacionais focam seus investimentos, prioritariamente, em políticas de avaliação de resultados, materializadas em exames externos de larga escala, padronizadas, aplicadas em determinados momentos com o objetivo de monitorar o desempenho dos alunos, para assim corrigir possíveis insuficiências.

De acordo Esteban, observa-se que não há relação entre o exame e o que ocorre cotidianamente na sala de aula. Os processos pedagógicos vividos pelos alunos nas relações com seus pares (professores, alunos e demais funcionários) são invisibilizados, e esses são avaliados 
apenas por questões objetivas padronizadas com percursos e pontos de chegada rigidamente estabelecidos. (ESTEBAN, 2009). As práticas pedagógicas desenvolvidas no interior das escolas, com maior ou menor intensidade, são fundadas neste princípio em que se naturaliza o fracasso escolar e a avaliação é um elemento-chave que solidifica e sustenta a lógica perversa neoliberal. A avaliação, portanto, não é um conceito estéril, pelo contrário, marca intenções políticas que concorrem para construção de determinado modelo de sociedade.

Mais do que concepção teórica da educação, a avaliação, como prática social, permeia nossas vidas apresentando diversas funções. Avaliamos desde a roupa que vamos usar, até a comida que comemos, identificando se está saborosa ou não. Avaliamos se uma pessoa está bem vestida a partir das nossas referências, sinalizando o convívio diário com tal conceito. Observamos vários aspectos, realizando diversos julgamentos de valor sobre as coisas que nos rodeiam. Assim, avaliamos o tempo todo.

No caso da escola, a avaliação assume caráter sistemático e intencional diretamente relacionada com as práticas escolares. Sua função está dirigida para realizar os ajustes dos processos de ensinoaprendizagem, no sentido de garantir o aprendizado de todos os alunos.

O que se coloca como central é reconhecer com quais concepções de avaliação, e consequentemente, de aprendizagens estamos trabalhando. Segundo Fernandes (2009), a avaliação, desde a sua origem até os dias atuais, foi se tornando mais complexa e mais sofisticada. Evoluiu da concepção de sinônimo de medida, passando por descrições de padrões previamente estabelecidos, juízos de valor, até ser concebida baseada em processos negociados e interativos com aqueles que estão diretamente relacionados com a avaliação. Sua evolução de significado está diretamente relacionada aos contextos 
históricos e sociais em que surgia, além de materializar propósitos aos quais está ligada.

Apesar da separação esquemática apresentada acima, as diversas concepções sobre a avaliação aparecem no cotidiano escolar materializada por vezes, simultaneamente, podendo conviver com todas as perspectivas citadas, no interior da escola, o que sinaliza parte da complexidade a ser enfrentada quando se pensa em investigar/estudar a avaliação para além dos livros teóricos, buscando a sua materialização na prática cotidiana.

Dada a sua amplitude, faz-se necessário pensar em que referencial teórico-epistemológico será alicerçado o trabalho quando saímos do mero estudo. Conhecer o processo histórico da avaliação, localizando suas implicações sócio-históricas é de suma importância para identificar a qual modelo avaliativo nossas ações cotidianas estão interligadas. Precisamos na mesma medida, ser conhecedores deste cenário, fazer uma escolha política para direcionar nossas ações pedagógicas o mais conscientemente possível no sentido de trabalhar (ou não) "para conseguir que todos os alunos tenham acesso a uma educação que lhes permita sua plena integração na sociedade em que vivem". (FERNANDES, 2009 p.19).

Se o sucesso escolar, em termos teóricos, é algo recorrentemente desenhado em diversos documentos e discursos pedagógicos, sua efetivação no chão da escola não ocorre de forma linear e automática. Este fato pode ser facilmente percebido quando identificamos um número de crianças, mesmo escolarizadas, que ainda não dominam sequer o código escrito. Não basta apenas conhecer os diferentes trajetos percorridos pela concepção de avaliação. É imperativo colocála a favor do sucesso pedagógico do aluno, contribuindo para a sua emancipação, rompendo com a lógica neoliberal em que se sustenta o fracasso escolar. Temos, como nos propõe Esteban e Sampaio (2012), que

Olh@res, Guarulhos, v. 2, n. 1, p. 237-252. Maio, 2014. 
Clamar por uma ação pedagógica emancipadora, praticada cotidianamente, que reconheça crianças e jovens, de classes populares como sujeitos de conhecimento, com seus modos singularidades e próprios de aprendizagem, legitimando-os como sujeitos capazes que são de dizer, pensar, decidir, fazer escolhas, (re)elaborar as informações ás quais têm acesso, dentro e/ou fora da escola, criar produzir conhecimentos.

Tomada por tal desafio, assumo a tarefa de colaborar com o processo de aquisição da língua escrita do Zhang ${ }^{5}$, aluno da escola investigada que depois de 3 anos de escolarização, ainda não domina o código escrito, o que denuncia a negligência do seu direito à escolarização.

Zhang é um aluno assíduo, matriculado no $3^{\circ}$ ano do $1^{\circ}$ ciclo, filho de jovem-adulta $^{6}$, que escreve o seu nome de maneira bastante rudimentar. Em sua certidão de nascimento não consta a filiação paterna, apesar de fazer referência ao seu pai em uma de nossas atividades. É importante salientar que o adulto referido como pai renovou a matricula do aluno no ano de 2012. Seu responsável também apresenta escrita rudimentar. Zhang também é contemplado com o Programa Bolsa Família, além de ter passado por avaliação nutricional realizada pela FME na escola e estar tanto abaixo do peso quanto da estatura.

Falamos então de uma criança marcada por diversas exclusões sociais, sendo a escolar apenas mais uma delas, pois apesar de estar cotidianamente na escola ainda não domina o código escrito. Suas diferenças são transformadas em desigualdades, legitimando sua suposta dificuldade de aprendizagem. Ele é o aluno "desnutrido", com pais com baixa escolarização que não frequentam as reuniões da escola, além de ser categorizado como aluno $\mathrm{NEE}^{7}$.

\footnotetext{
5 Denomino o meu aluno parceiro de produção de texto e aprendizado de Zhang, primeiro em uma homenagem, pois este é nome do aluno protagonista do filme que desafia a professora tal qual o meu aluno faz comigo, além de desta forma guardar o seu anonimato, garantindo o caráter ético da pesquisa.

${ }^{6}$ Pela sua certidão é evidenciado que sua mãe a época do parto tinha 18 anos.

${ }^{7} \mathrm{NEE}$ - aluno declarado com necessidades educacionais especiais atendidos pela equipe de educação especial, sala de recursos e professor de apoio.
}

Olh@res, Guarulhos, v. 2, n. 1, p. 237-252. Maio, 2014. 
Zhang é apenas um dos vários alunos presentes na escola oriundos das classes populares e que a escola pública tem o dever políticopedagógico de atender. Ocorre que este aluno concreto, "que vive neste mundo real, os professores parecem considerar muito difícil, senão impossível de ensinar" (COLLARES e MOYSÉS, 1996, p.26). Os professores explicitam que os alunos como ele não aprendem porque têm dificuldades pedagógicas e sociais. Assim a diferença cultural e social dos alunos é invisibilizada e transformada em problemas de naturezas diversas, tais como socioeconômicos e/ou de saúde que justificam o seu fracasso escolar e com Zhang não é diferente, ou seja,

Não aprendem porque são pobres, porque são negras, porque são nordestinas, ou provenientes de zona rural, são preguiçosas, não aprendem porque seus pais são analfabetos, são alcoólatras, as mães trabalham fora, não ensinam a seus filhos (COLLARES e MOYSÉS, 1996 p.26)

Ocorre assim, o apagamento das diferenças sociais e culturais, pois só há uma única forma de ser, uma única cultura, um único conhecimento válido, o conhecimento científico. Culturas que não estão alicerçadas na racionalidade científica não são legitimadas e suas crenças, valores, formas de ser e estar no mundo, são consideradas menores, ou até inexistentes, sendo necessário que as classes populares sejam educadas, em outras palavras, aculturadas ou ainda civilizadas.

Nesta distribuição social do conhecimento, o pobre e o negro, para não falar em outras diferenças socioculturais, são colocados à margem e a escola e suas práticas pedagógicas, incluindo a avaliação, irão sorrateiramente contribuindo para este cenário social.

Havendo apenas uma cultura, só temos um conhecimento válido, logo um currículo único que deve ser uniformizado, homogeneizado e transmitido a todos os alunos, independentemente de sua origem social. Zhang vai internalizando seu fracasso, pois, conforme citado 
anteriormente, encontra-se apartado deste universo cultural e social preconizado.

A aprendizagem, neste cenário é traduzida em desempenho, que deve ser quantificado, classificado e hierarquizado, mantendo eternamente o aluno oriundo das classes populares no lugar de pobre e que não consegue aprender, apesar de lhe ser facultado o direito à educação, autorizando assim o seu acesso e não o seu sucesso escolar.

Para romper com este circulo vicioso, além da análise da conjuntura em que tal fenômeno ocorre, faz-se premente a adoção de estratégias pedagógicas que estejam comprometidas com o aprendizado dos alunos estabelecidas em relações horizontalizadas de diálogo. Assim começo a minha busca por Zhang.

\section{A busca por Zhang: é possível não deixar ninguém para trás?}

Para colaborar com o processo de ensinoaprendizagem ${ }^{8}$ de Zhang, é necessário romper com a ideia de igualdade compreendida como neutralidade das diferenças, sendo necessário buscar outras referências de avaliação e de aprendizagem. A avaliação relacionada estritamente a premiar e punir deve ser abolida, mas a alternativa a tal modelo avaliativo não pode ser entendida como a salvação dos problemas pedagógicos, e sim, com um dos aspectos da educação que pode (ou não) favorecer a transformação.

Compreender a avaliação com a finalidade de fazer o aluno crescer em seus processos de aprendizagem, então, é um possível caminho a ser seguido em que a aprendizagem não se restringe ao desempenho, para Fernandes,

As aprendizagens significativas, as chamadas aprendizagens com compreensão ou aprendizagens profundas, são reflexivas, construídas ativamente pelos alunos e autorreguladas. Por isso, eles não são encarados como meros receptores que se limitam a "gravar" informação, mas antes

\footnotetext{
${ }^{8}$ Assumidos como elementos indissociáveis, conforme estudos de Alves e Garcia, 1999
}

Olh@res, Guarulhos, v. 2, n. 1, p. 237-252. Maio, 2014. 
como sujeitos ativos na construção de suas estruturas de conhecimento. Conhecer alguma coisa significa ter se interpretá-la e ter de relacioná-la com outros conhecimentos já adquiridos." (Fernandes, p.33 2009.)

Assim, a aprendizagem, e consequentemente, a avaliação são partes constitutivas e indissociáveis que favorecem o conhecimento. Não são compreendidos como elementos coercitivos e prescritivos que homogeneízam as relações. Ao contrário, partem do reconhecimento da aprendizagem ativa e reguladora promovida pelos alunos em que estes são sujeitos ativos em seus processos educativos, apresentando caráter participativo, subjetivo e relacional. Nesses termos, para o mesmo autor, a avaliação da aprendizagem,

pode ser entendida como todo e qualquer processo
deliberado e sistemático de coleta de informação mais
ou menos participativo e interativo, mais ou menos
negociado, mais ou menos contextualizado, acerca do
que os alunos sabem e são capazes de fazer em uma
diversidade de situações." (FERNANDES, 2009, p. 20)

A avaliação e a aprendizagem devem ser pautadas no diálogo em que o outro tem o que dizer, ou seja, o outro, o aluno, é alguém com legitimidade para dizer. Dizer sobre a sua cultura, sua condição social, sua forma de estar no mundo, entendidos como elementos de sua história que não devem ser marginalizados. Podem e devem ser problematizados, sinalizando a dimensão reflexiva presente, tanto nos aspectos macro de sua existência, como micro dos seus fazeres pedagógicos, ou seja, o processo educativo pode favorecer a compreensão das questões sociais em que o aluno e o professor encontram-se mergulhados e dos processos de ensinoaprendizagem vividos na relação pedagógica. A base do trabalho pedagógico é a reflexão compreendida com caráter investigativo.

Alicerçada nas premissas assinaladas acima, inicio um trabalho com Zhang na tentativa de transformar as práticas pedagógicas vividas em aprendizagens mais significativas, a partir das redes de saberes construídos por ele. Assim, o diálogo será o alicerce do trabalho com Zhang, estimulando-o e desafiando-o a realizar novas aprendizagens

Olh@res, Guarulhos, v. 2, n. 1, p. 237-252. Maio, 2014. 
certezas sobre o não aprendizado do aluno, se não evidencio para o grupo de professores, e para o aluno, o seu potencial de aprendizagem? Tomada pelos questionamentos da referida pesquisa e pelo suposto insucesso do aluno, busco estratégias que possibilitem compreender o caminho percorrido por ele.

Em termos teórico-práticos, tal estratégia se coloca como desafio, não só para o aluno, mas para mim, professora-pedagoga, que deverei assumir olhar investigativo sobre o cotidiano do Zhang quando busco observar como ele opera nas resoluções dos esquemas pedagógicos apresentados, indicando o caminho a ser trilhado. Então investigo o Zhang ao mesmo tempo em que me investigo, colocando determinadas certezas pedagógicas em xeque.

Para materializar parte do nosso percurso de ensinoaprendizagem, apresento breve relato do trabalho pedagógico desenvolvido, resultado de nossas interações em que questiono a ideia de dificuldade de aprendizagem de Zhang, estabelecendo outras relações de aprendizagem em que a falta não é a referência.

Em um de nossos encontros, falo para Zhang que para ensinar, é necessário conhecer... Conhecer com quem estamos trabalhando. Proponho então que desenhe a sua família. Nesta hora também solicito que escreva os seus nomes. Ele escreve o seu nome e diz que não sabe escrever o nome de mais ninguém. Identifico que ele tem um irmão com o nome em que a grafia é semelhante à sua. Problematizo com ele tais semelhanças entre os nomes. Zhang percebe que sabe escrever o nome do seu irmão também. Finalizo o trabalho pedindo que ele pinte o desenho. Ele faz uma pipa e eu novamente o desafio a escrever; reluta, mas coloca as letras I e A para escrever a palavra solicitada. Percebo que Zhang começa a evidenciar o que já sabe da escrita. 
Pego os nomes que trabalhamos: os da sua família e o meu e os divido na sua frente. Corto as palavras em sílabas. Temos então, a palavra escrita corretamente e por inteiro e a palavra dividida. Faço um jogo de quebra-cabeça e Zhang consegue remontar todas as palavras trabalhadas. Ele, durante estas atividades, evidencia que:

- faz hipótese silábica para escrever Pipa;

- Reconhece a diferença entre o seu nome e o do irmão e consegue escrevê-los;

- Consegue encontrar as palavras trabalhadas e remontá-las a partir de suas partes.

Neste pequeno relato de encontro e de diálogo, é possível desconstruir certezas cristalizadas sobre o aluno, aquele que nada sabia; a quem seria impossível ensinar; apresenta pistas de seu aprendizado, de suas inferências. Afastando-se do olhar da falta, do que nada sabe, assumindo que esse aluno tem saberes que a escola por vezes ignora, conhecemos um aluno com diversas potencialidades. $\mathrm{O}$ discurso dos seus professores em que apresentam o Zhang como aluno que não faz relação sonora, não reconhece as letras do alfabeto e não faz hipótese sobre a leitura e a escrita, é desconstruído em apenas um encontrodiálogo. Por que ninguém via a sua produção? Por que o que ele sabe não foi reconhecido como conhecimento legítimo?

Ocorre que suas respostas não se encaixam no que é esperado na medida em que o aprendizado é restrito ao desempenho único e universal, suas inferências são identificadas como insatisfatórias para o seu ano de escolaridade. Fora do padrão, Zhang é reduzido apenas ao aluno que não aprende, pois é pobre, desnutrido e com uma família desestruturada, legitimando o seu fracasso sem outros caminhos possíveis de serem trilhados.

Não observamos, nos discursos dos professores, e por vezes até do aluno, o reconhecimento de seu aprendizado. Não são levados em Olh@ res, Guarulhos, v. 2, n. 1, p. 237-252. Maio, 2014. 
necessita de propostas diversificadas e que a professora em sala de aula não pôde realizar. Legitima-se assim, que o pobre, o desnutrido, com pais com baixa escolarização devem ser direcionados para projetos pedagógicos específicos, Para Freitas, alunos como Zhang,

...desacreditados nas salas de aula, ou relegados a programas de recuperação, aceleração, progressão continuada e/ou automática, educação de jovens e adultos, pseudo-escolas de tempo integral, cuja eliminação foi suspensa ou adiada e aguardam sua eliminação definitiva" ( FREITAS, 2007, p. 968)

Observa-se assim o potencial dual presente na ação pedagógica desenvolvida, a proposta que corrobora o seu aprendizado, também pode segregá-lo e apenas adiar o fracasso escolar, pois ao retirá-lo de sala materializo o seu fracasso, sustentando que só é possível resolver suas "dificuldades" em um espaço diferenciado, e que a professora de sala regular não tem como trabalhar com aquele aluno, juntos com os demais; assim sua condição social serve de justificativa para sua exclusão. Não deixar nenhum aluno para trás como opção política significa garantir o aprendizado de todos os alunos independentemente de sua condição socioeconômica. Ocorre que a simples adoção do discurso não garante o sucesso do aluno, se as bases teóricoepistemógicas estiverem a favor da lógica liberal. No USA, por exemplo, no ano de 2002 foi aprovada a Lei denominada No Child Left Behing, que dá consequência ao sistema de prestação de contas baseado em resultados. É um sistema regulatório que concorre para a manutenção das desigualdades sociais, pois os resultados esperados, fruto do mérito dos alunos e das escolas, são estrategicamente divulgados, institucionalizando a escola para ricos e a escola para pobres. (FREITAS, 2007). Apesar do discurso de garantia do aprendizado para todos, não deixando ninguém para trás, a partir da ideologia meritocrática, tal estratégia limita-se à medição do mérito por meio do desempenho e ocultação das diferenças sociais, não havendo, portanto, o real propósito de garantir o aprendizado de todos os alunos, apenas alguns são eleitos e merecedores deste legado social, o conhecimento socialmente construído e válido. 
Apesar do cenário das políticas educacionais, tecidas em um contexto em que as concepções neoliberais se apresentam como hegemônicas, o território escolar ainda é, sem dúvida, um importante espaço-tempo de disputas. Mesmo com pouca possibilidade, no cotidiano escolar, para a articulação entre o conhecimento das classes populares e as práticas avaliativas (comprometidas com aprendizado dos alunos e não com o desempenho), é possível desenhar caminhos que favoreçam a construção de saberes para todos os alunos. As práticas normatizantes e as emancipadoras, que convivem e disputam o território pedagógico, reveladas nos discursos e nas ações pedagógicas dos docentes, abrem brechas e desvios que têm potencial para transformar as relações desenvolvidas no âmbito da instituição escolar, e assim podem favorecer a construção de uma sociedade mais justa e menos excludente.

Ao trabalhar com a avaliação comprometida com a aprendizagem, e não com o desempenho, podemos estabelecer relações dialógicas que propiciem processos pedagógicos mais democráticos que horizontalizem sujeitos, contextos sociais e conhecimento. Neste sentido, avalio para redefinir práticas, compreender caminhos cognitivos e não para classificar e hierarquizar saberes, que consequentemente, segregam e excluem sumariamente as classes populares de seu direito subjetivo à educação e ao conhecimento socialmente construído. 


\section{Referência}

ALVES, N. e GARCIA, R. L. (org). O sentido da escola. Rio de Janeiro, DP\&A, 1999.

COLlARES, Cecília A. L.; MOYSÉS, M. Aparecida A. Preconceitos no cotidiano escolar: ensino e medicalização. São Paulo: Cortez, 1996.

FERNANDES, D. Avaliar para aprender: Fundamentos, práticas e políticas. São Paulo: Unesp. $1^{\text {a }}$ edição. 2009.

ESTEBAN, M T: Currículos e conhecimentos escolares. In: FERRAÇO, Carlos Eduardo; CARVALHO, Janete Magalhães (org.). Currículos, pesquisas, conhecimentos e produção de subjetividades. Petrópolis, RJ: DP et Alii, 2012, v. 1, p. 119-141.

Provinha Brasil: desempenho escolar e discursos normativos sobre a infância. Sísifo: Revista de Ciências da Educação, n. 9, p. 47-56, 2009.

ESTEBAN e SAMPAIO: Diferença, alteridade e aprendizagem: Desafios infantis ao saber docente. XVI ENDIPE- Unicamp; Campinas: Junqueira e Marin editores, 2012.

FREITAS, Os reformadores empresariais da educação: da desmoralização do magistério à destruição do sistema público de educação. Educ. Soc., Campinas 33.119 (2012): 379-404. Disponível em 〈http://www.scielo.br/pdf/es/v33n119/a04v33n119.pdf>. Acesso em 03/01/2014.

FREITAS, L. C. de. Eliminação adiada: o ocaso das classes populares no interior da escola e a ocultação da (má) qualidade do Ensino. Educação e Sociedade. Campinas, vol. 28, n. 100 - Especial, p. 965-987, out. 2007. 